\title{
Identification of Basic Amino Acid Residues Important for Citrate Binding by the Periplasmic Receptor Domain of the Sensor Kinase CitA
}

\author{
Tanja Gerharz,,${ }^{\ddagger}$ Stefan Reinelt, ${ }^{\S, \|}$ Sibylle Kaspar,, Leonardo Scapozza, ${ }^{\S}$ and Michael Bott*, ${ }^{\star}$ \\ Institut für Biotechnologie 1, Forschungszentrum Jülich, D-52425 Jülich, Germany, and Departement Pharmazie, \\ Eidgenössische Technische Hochschule, Winterthurerstrasse 190, CH-8057 Zürich, Switzerland
}

Received January 13, 2003

\begin{abstract}
The sensor kinase CitA and the response regulator CitB of Klebsiella pneumoniae form the paradigm of a subfamily of bacterial two-component regulatory systems that are capable of sensing trior dicarboxylates in the environment and then induce transporters for the uptake of these compounds. We recently showed that the separated periplasmic domain of CitA, termed CitAP (encompasses residues 45-176 supplemented with an $\mathrm{N}$-terminal methionine residue and a $\mathrm{C}$-terminal hexahistidine tag), is a highly specific citrate receptor with a $K_{\mathrm{d}}$ of $5.5 \mu \mathrm{M}$ at $\mathrm{pH}$ 7. To identify positively charged residues involved in binding the citrate anion, each of the arginine, lysine, and histidine residues in CitAP was exchanged for alanine, and the resulting 17 muteins were analyzed by isothermal titration calorimetry (ITC). In 12 cases, the $K_{\mathrm{d}}$ for citrate was identical to that of wild-type CitAP or slightly changed (3.9$17.2 \mu \mathrm{M})$. In one case (R98A), the $K_{\mathrm{d}}$ was 6 -fold decreased $(0.8 \mu \mathrm{M})$, whereas in four cases (R66A, H69A, R107A, and K109A) the $K_{\mathrm{d}}$ was 38 - to $>300$-fold increased $(0.2$ to $>1 \mathrm{mM})$. The secondary structure of the latter five proteins in their apo-form as deduced from far-UV circular dichroism (CD) spectra did not differ from the apo-form of wild-type CitAP; however, all of them showed an increased thermostability. Citrate increased the melting point $\left(T_{\mathrm{m}}\right)$ of wild-type CitAP and mutein R98A by 6.2 and $9.5^{\circ} \mathrm{C}$, respectively, but had no effect on the $T_{\mathrm{m}}$ of the four proteins with disturbed binding. Three of the residues important for citrate binding (R66, H69, and R107) are highly conserved in the CitA subfamily of sensor kinases, indicating that they might be involved in ligand binding by many of these sensor kinases.
\end{abstract}

In bacteria, adaptive responses to changing environmental conditions are often accomplished by two-component regulatory systems, which in their simplest form consist of two modular proteins, a sensor kinase, and a response regulator. The sensor kinase responds to a certain stimulus by autophosphorylation of a conserved histidine residue, and the phosphoryl group is subsequently transferred to a conserved aspartate residue of the response regulator, which triggers changes in gene expression or cell behavior depending on its phosphorylation status $(1-4)$. In the majority of cases, sensor kinases are transmembrane proteins with an extracellular N-terminal sensor domain (typically 100-200 amino acids in length) flanked by two transmembrane helices and a cytoplasmic C-terminal autokinase core ( 220 amino acids) that is connected to the second transmembrane helix either by a short linker region or by an additional domain. This architecture enables the proteins to sense external stimuli and transduce information to the cytoplasm.

A typical representative of these proteins is the sensor kinase CitA from the enterobacterium Klebsiella pneumoniae (Figure 1). Together with its cognate response regulator $\mathrm{CitB}$, it induces the expression of genes encoding enzymes that

* Corresponding author. Tel.: +49-(0)2461-615515. Fax: +49-(0)2461-612710. E-mail: m.bott@fz-juelich.de.

$\stackrel{+}{*}$ Forschungszentrum Jülich.

$\S$ Eidgenössische Technische Hochschule.

"Present address: Max-Planck-Institut für medizinische Forschung, Jahnstrasse 29, D-69120 Heidelberg, Germany.

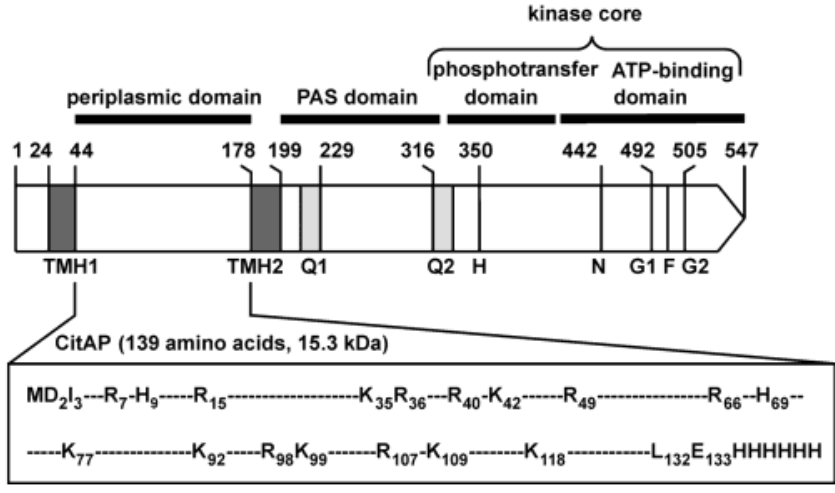

FIGURE 1: Schematic representation of the domain organization of the $K$. pneumoniae sensor kinase and of the arginine, lysine, and histidine residues within CitAP. Abbreviations: TMH, transmembrane helix; Q, Q linker (30); H, H-box containing the conserved autophosphorylated histidine residue; N, G1, F, G2, conserved boxes involved in ATP binding; PAS, acronym formed from the names of the proteins in which the features characteristic for this signaling module were first recognized (31).

are involved in citrate fermentation $(5,6)$ (i.e., the sodiumdependent citrate carrier CitS (7), citrate lyase $(8-10)$, and the sodium-ion pump oxaloacetate decarboxylase $(11-13)$ ). Expression requires the presence of citrate, sodium ions, and anoxic conditions (5) and is subject to catabolite repression (14). It was recently shown that the periplasmic domain of the sensor kinase CitA serves as a highly specific citrate receptor (15). The periplasmic domain (residues 45-176) 


\begin{tabular}{|c|c|c|}
\hline name & sequence $\left(5^{\prime} \rightarrow 3^{\prime}\right)$ & new r.s. \\
\hline R7f & ATTACCGAGGAAGCTTTGCATTATCAGGTC & HindIII \\
\hline H9f & ACCGAGGAGCGGCTAGCTTATCAGGTCGGG & NheI \\
\hline $\mathrm{R} 15 \mathrm{f}$ & CAGGTCGGGCAAGCGGCATTAATTCAGGCGATGCAGATTTCG & AsnI \\
\hline K35f & GAGGCAGTGCAGGCGCGCGATCTCGCC & BssHII \\
\hline $\mathrm{R} 36 \mathrm{f}$ & GCAGTGCAGAAAGCAGATCTCGCCAGA & $B g l \mathrm{II}$ \\
\hline R40f & AAACGAGATCTCGCCGCAATCAAAGCCCTT & $B g l I I$ \\
\hline K42f & CGCGATCTCGCGCGCATCGCAGCCCTTATCGAC & BssHII \\
\hline $\mathrm{R} 49 \mathrm{f}$ & CTTATCGACCCCATGGCTTCGTTCTCCGAC & NcoI \\
\hline R66f & GATGCCAGCGGCCAGGCCCTGTATCACGTCAAT & MvaI \\
\hline H69f & CAGCGCCTCTATGCCGTTAACCCTGATGAA & HpaI \\
\hline K77f & GATGAAATCGGCGCCTCGATGGAAGGC & NarI \\
\hline K92f & GAGGCGTTGATTAATGCTGCAAGCTACGTGTCA & AsnI \\
\hline R98f & AGCTACGTGTCAGTCGCGAAAGGCTCGCTG & NruI \\
\hline K99f & GTGTCAGTGCGCGCAGGATCCCTGGGATCG & BamHI \\
\hline $\mathrm{R} 107 \mathrm{f}$ & GGATCGTCGCTGGCCGGCAAATCGCCG & NaeI \\
\hline K109f & TCGCTGCGCGGTGCTAGCCCGATTCAGGAC & NheI \\
\hline $\mathrm{K} 118 \mathrm{f}$ & GACGCAACCGGCGCCGTGATCGGCATT & NarI \\
\hline
\end{tabular}

${ }^{a}$ Only the sequence of the forward primers is shown, that of the reverse primers (R7r, H9r, etc.) is exactly complementary to the corresponding forward primers. The last column designated New r.s. lists the new restriction sites introduced into plasmid pET-CitAP for the easy identification of positive clones.

was overproduced as a soluble, cytoplasmic protein with a carboxyterminal hexahistidine tag, termed CitAP (Figure 1), and purified by $\mathrm{Ni}^{2+}-\mathrm{NTA}^{1}$ affinity chromatography. Binding studies with CitAP using either ${ }^{14} \mathrm{C}$-labeled citrate or ITC revealed that CitAP bound citrate with a $K_{\mathrm{d}}$ of $5.5 \mu \mathrm{M}$ in 50 $\mathrm{mM}$ sodium phosphate buffer $\mathrm{pH}$ 7. Binding was driven by the enthalpy change $(\Delta H=-76.3 \mathrm{~kJ} / \mathrm{mol})$, whereas the entropy change was unfavorable $(T \Delta S=-46.3 \mathrm{~kJ} / \mathrm{mol})$. Under the conditions tested, CitAP behaved as a monomeric protein, independent of the presence or absence of citrate. Binding was strongly dependent on the $\mathrm{pH}$, with a maximal affinity at $\mathrm{pH}$ 5.7, at which the concentration of the divalent citrate species $\mathrm{H}$-citrate ${ }^{2-}$ is maximal. This was used as an argument that $\mathrm{H}$-citrate ${ }^{2-}$ is the ligand bound by CitAP (15).

Binding of a 2-fold negatively charged citrate ion to CitAP might involve positively charged amino acid residues. Therefore, each of the arginine, lysine, and histidine residues in CitAP was exchanged to the neutral amino acid alanine, and after purification the resulting 17 mutated CitAP derivatives were analyzed for citrate binding by ITC. In addition, the structure and thermal stability of selected CitAP mutants were studied by CD spectroscopy. In this way, five residues were identified that are highly important for citrate binding.

\section{EXPERIMENTAL PROCEDURES}

Bacterial Strains and Growth Conditions. For the propagation and isolation of mutated derivatives of plasmid pETCitAP, supercompetent cells of Escherichia coli XL1-Blue (Stratagene) were used. For the overproduction of the mutated CitAP derivatives, E. coli BL21(DE3) (16) was used. The strains were routinely cultivated aerobically at $37{ }^{\circ} \mathrm{C}$ in Luria-Bertani medium (10 g/L tryptone, $5 \mathrm{~g} / \mathrm{L}$ yeast extract, $5 \mathrm{~g} / \mathrm{L} \mathrm{NaCl}$ ) supplemented with $50 \mu \mathrm{g} / \mathrm{mL}$ kanamycin.

Construction of CitAP Derivatives Containing Single ArgAla, Lys-Ala, or His-Ala Exchanges. CitAP is a derivative of the sensor kinase CitA from $K$. pneumoniae encompassing residues 45-176 supplemented with an N-terminal methion-

\footnotetext{
${ }^{1}$ Abbreviations: CD, circular dichroism; HPK, histidine protein kinase; ITC, isothermal titration calorimetry; NTA, nitrilotriacetic acid.
}

ine residue and a C-terminal hexahistidine tag (Figure 1). The protein is encoded by plasmid pET-CitAP, and its synthesis is controlled by a phage $\mathrm{T} 7$ promoter and the translation initiation signals of the gene 10 protein of phage T7 (15). To exchange each of the nine arginine, six lysine, and two histidine residues within CitAP by alanine, pETCitAP was subjected to site-directed mutagenesis using the QuikChange site-directed mutagenesis kit according to the instructions of the supplier (Stratagene, Heidelberg, Germany). The oligonucleotides used for mutagenesis (Table 1) contained not only the mutations required for the desired amino acid exchange but also silent mutations that introduced new restriction sites into pET-CitAP. In this way, the plasmids obtained after mutagenesis could be first screened by restriction mapping for those containing the mutation. The CitAP coding region of these plasmids was then sequenced on both strands (17) to confirm that no spurious mutations had been introduced.

Overproduction and Purification of CitAP Derivatives Containing Single Arg-Ala, Lys-Ala, or His-Ala Exchanges. For the purification of the mutated CitAP derivatives, the corresponding plasmids were transferred to E. coli BL21 (DE3). Cultivation of the transformed cells and purification by $\mathrm{Ni}^{2+}$-NTA affinity chromatography of the mutated CitAP derivatives were performed as described for wild-type CitAP (15). The purity of the proteins was checked by SDSpolyacrylamide gel electrophoresis and staining of the gels with colloidal Coomassie (Pierce, Rockford, IL). Protein concentrations were determined spectrophotometrically at $280 \mathrm{~nm}$ using an extinction coefficient of $6.4 \mathrm{mM}^{-1} \mathrm{~cm}^{-1}$ (18). In some cases, the protein solutions were concentrated using Centricon-3 or Centricon-10 ultracentrifugation devices (Millipore, Eschborn, Germany) before being used for ITC measurements.

Mass Spectrometric Analysis of CitAP Muteins. To confirm the amino acid exchanges in the mutated CitAP proteins, several of them were analyzed by peptide mass fingerprinting. To this end, the desired protein spots were excised from Coomassie-stained SDS- polyacrylamide gels and subjected to digestion in the gel with trypsin as described (19). The trypsinogenic peptides were extracted and analyzed using a 
Table 2: Thermodynamic Parameters for Citrate Binding to Wild-Type CitAP and 17 CitAP Muteins as Determined by Isothermal Titration Calorimetry ${ }^{a}$

\begin{tabular}{lcccccc}
\hline protein & $n$ & $\begin{array}{c}K_{\mathrm{d}} \\
(\mu \mathrm{M})\end{array}$ & $\begin{array}{c}K_{\mathrm{d}} \text { (mutein)/ } \\
K_{\mathrm{d}}(\text { wild type })\end{array}$ & $\begin{array}{c}\Delta H \\
(\mathrm{~kJ} / \mathrm{mol})\end{array}$ & $\begin{array}{c}T \Delta S \\
(\mathrm{~kJ} / \mathrm{mol})\end{array}$ \\
\hline Wt & $0.95 \pm 0.06$ & $5.3 \pm 1.1$ & 1.0 & $-80.3 \pm 8.7$ & $-48.7 \pm 9.0$ & $-30.7 \pm 0.6$ \\
R7A & $0.51 \pm 0.03$ & $6.0 \pm 0.1$ & 1.1 & $-45.8 \pm 0.9$ & $-16.0 \pm 0.9$ & $-29.8 \pm 0.1$ \\
H9A & $0.87 \pm 0.03$ & $9.8 \pm 1.4$ & 1.9 & $-45.2 \pm 2.8$ & $-16.6 \pm 3.1$ & $-28.6 \pm 0.3$ \\
R15A & $0.94 \pm 0.02$ & $9.3 \pm 2.8$ & 1.8 & $-48.6 \pm 1.2$ & $-19.8 \pm 0.6$ & $-28.8 \pm 0.7$ \\
K35A & $0.74 \pm 0.01$ & $4.8 \pm 0.7$ & 0.9 & $-67.9 \pm 1.4$ & $-36.7 \pm 3.0$ & $-31.2 \pm 1.6$ \\
R36A & $0.73 \pm 0.01$ & $4.3 \pm 0.3$ & 0.8 & $-73.9 \pm 8.4$ & $-43.3 \pm 8.6$ & $-30.6 \pm 0.2$ \\
R40A & $0.69 \pm 0.01$ & $4.6 \pm 0.4$ & 0.9 & $-71.3 \pm 2.0$ & $-40.8 \pm 2.2$ & $-30.5 \pm 0.2$ \\
K42A & $0.74 \pm 0.02$ & $7.0 \pm 0.6$ & 1.3 & $-59.1 \pm 3.1$ & $-29.7 \pm 3.2$ & $-29.4 \pm 0.2$ \\
R49A & $0.63 \pm 0.04$ & $16.7 \pm 5.0$ & 3.2 & $-80.3 \pm 5.8$ & $-52.9 \pm 6.2$ & $-27.4 \pm 0.7$ \\
R66A & $(1.00$, fixed) & $(7067 \pm 42)$ & $(1333)$ & $(-1.9 \pm 1.0)$ & $(10.4 \pm 1.0)$ & $(-12.3 \pm 0.1)$ \\
H69A & $(0.68 \pm 0.18)$ & $(2087 \pm 767)$ & $(394)$ & $(-32.9 \pm 0.1)$ & $(-17.6 \pm 0.1)$ & $(-15.4 \pm 0.1)$ \\
K77A & $0.56 \pm 0.15$ & $17.2 \pm 3.9$ & 3.3 & $-84.4 \pm 8.0$ & $-57.1 \pm 8.3$ & $-27.3 \pm 0.6$ \\
K92A & $1.23 \pm 0.25$ & $12.2 \pm 1.0$ & 2.3 & $-66.9 \pm 3.5$ & $-38.9 \pm 3.8$ & $-28.0 \pm 0.2$ \\
R98A & $0.30 \pm 0.01$ & $0.8 \pm 0.1$ & 0.2 & $-56.6 \pm 5.8$ & $-21.9 \pm 5.5$ & $-34.7 \pm 0.3$ \\
K99A & $0.77 \pm 0.03$ & $4.7 \pm 1.3$ & 0.9 & $-61.6 \pm 0.4$ & $-31.2 \pm 1.1$ & $-30.5 \pm 0.7$ \\
R107A & $1.36 \pm 0.18$ & $205 \pm 35$ & 38.7 & $-61.5 \pm 2.1$ & $-40.5 \pm 1.7$ & $-21.1 \pm 0.4$ \\
K109A & $(0.53 \pm 0.03)$ & $(2054 \pm 1949)$ & $(388)$ & $(64.5 \pm 0.6)$ & $(46.3 \pm 3.4)$ & $(18.2 \pm 2.8)$ \\
K118A & $0.79 \pm 0.02$ & $3.9 \pm 0.6$ & 0.7 & $-71.0 \pm 4.2$ & $-40.1 \pm 4.5$ & $-30.9 \pm 0.4$ \\
\hline
\end{tabular}

${ }^{a}$ All experiments were performed at $25^{\circ} \mathrm{C}$ in $50 \mathrm{mM}$ sodium phosphate buffer $\mathrm{pH}$ 7.0. The values represent the mean of at least two experiments. The binding stoichiometry is indicated as $n$. The values given in parantheses represent estimates rather than accurate data since in the corresponding experiments the $c$ value, defined as the total protein concentration multiplied with the binding constant (20), was $\leq 1$ and therefore too low to obtain reliable data (32).

MALDI-TOF mass spectrometer (Voyager STR, Applied Biosystems, Weiterstadt, Germany) as reported previously (19).

Isothermal Titration Calorimetry. All ITC measurements were performed using a VP-ITC microcalorimeter from MicroCal (Northampton, MA) with a cell volume of 1.40 $\mathrm{mL}$ at a temperature of $25^{\circ} \mathrm{C}$. Automated injections were made with a $250 \mu \mathrm{L}$ microsyringe while stirring at $310 \mathrm{rpm}$. The calorimeter and the equations used to fit calorimetric data have been described in detail previously (20). The reference cell was filled with water. Prior to loading into the microcalorimeter, the solutions were degassed for $10 \mathrm{~min}$ with gentle swirling under vacuum. All ITC measurements were performed in $50 \mathrm{mM}$ sodium phosphate buffer $\mathrm{pH} 7.0$, and the purified CitAP derivatives were extensively dialyzed against this buffer before being used for ITC. Solutions of the protein $(62-2340 \mu \mathrm{M})$ were filled into the sample cell and titrated with citrate using identical injections of 3-10 $\mu \mathrm{L}$. Sodium citrate was dissolved in the final dialysis buffer to a concentration 11-57 times higher than the protein concentration. Calorimetric data were analyzed using the ORIGIN software Version 5.0 (MicroCal, Northampton, MA). All binding parameters presented in Table 2 are the means of at least two experiments.

CD Spectroscopy. Prior to analysis by CD spectroscopy, the solution of purified CitAP was dialyzed against $50 \mathrm{mM}$ sodium phosphate buffer $\mathrm{pH}$ 7.0. Citrate was added before the measurements to a final concentration of $10 \mathrm{mM}$. All CD spectra were recorded with a JASCO J720 spectropolarimeter at $20^{\circ} \mathrm{C}$. For far-UV spectra $(185-260 \mathrm{~nm})$, a 0.1 cm cuvette was used, for near-UV-spectra $(260-380 \mathrm{~nm})$ a $0.5 \mathrm{~cm}$ cuvette. The protein concentration used for all measurements was $1 \mathrm{mg} / \mathrm{mL}$, corresponding to a CitAP concentration of $65 \mu \mathrm{M}$. For protein and buffer solutions, the spectra of three scans were averaged. Protein spectra were converted to molar ellipticity after subtraction of the corresponding buffer spectrum. Estimates of secondary structure were obtained by using software provided by JASCO.
Thermal Denaturation of CitAP. Thermal denaturation was monitored by CD spectroscopy at a wavelength of $218 \mathrm{~nm}$. Samples were prepared as described for far-UV CD spectroscopy. The temperature was increased from 25 to $90{ }^{\circ} \mathrm{C}$ at a rate of $30{ }^{\circ} \mathrm{C} / \mathrm{h}$. The midpoint of the transition curve $\left(T_{\mathrm{m}}\right)$ was determined by a fit to a two-state unfolding model following a standard protocol (21). When the temperature was decreased from 90 to $25^{\circ} \mathrm{C}$, about $90 \%$ of the initial $\mathrm{CD}$ signal at $25^{\circ} \mathrm{C}$ was recovered; therefore, the process can be considered reversible. A subsequent increase to 90 ${ }^{\circ} \mathrm{C}$ led to the same $T_{\mathrm{m}}$ value as in the first denaturation.

\section{RESULTS}

Construction, Purification, and Mass Spectrometry of Mutated CitAP Proteins. CitAP is a derivative of the sensor kinase CitA from $K$. pneumoniae comprising the periplasmic domain of this protein (amino acids 45-176) supplemented with an N-terminal methionine residue and a C-terminal hexahistidine tag (15). To exchange all arginine, lysine, and histidine residues (except that of the His tag) for alanine, plasmid pET-CitAP was subjected to site-directed mutagenesis as described in the Experimental Procedures. The 17 CitAP muteins were overproduced in E. coli BL21(DE3) and purified by $\mathrm{Ni}^{2+}$-NTA affinity chromatography as described for wild-type CitAP (15). None of the mutations led to a significant decrease in solubility, and all proteins showed the expected size of $15 \mathrm{kDa}$ and were highly pure $(>98 \%)$ when analyzed by SDS-polyacrylamide gel electrophoresis and staining with Coomassie (see Figure 5 in ref 15). On average, $25 \mathrm{mg}$ of protein was obtained from $1 \mathrm{~g}$ of cells (wet weight), and the concentration after affinity chromatography ranged from 5 to $14 \mathrm{mg} / \mathrm{mL}(0.3-0.9 \mathrm{mM})$. Using peptide mass fingerprinting by MALDI-TOF mass spectrometry, several of the amino acid exchanges (R7A, H9A, K42A, H69A, K77A, K92A, and K109A) in the muteins were confirmed at the protein level (data not shown). The numbers used to designate specific mutations refers to the amino acid position in CitAP. To obtain the corresponding 
Time (min)

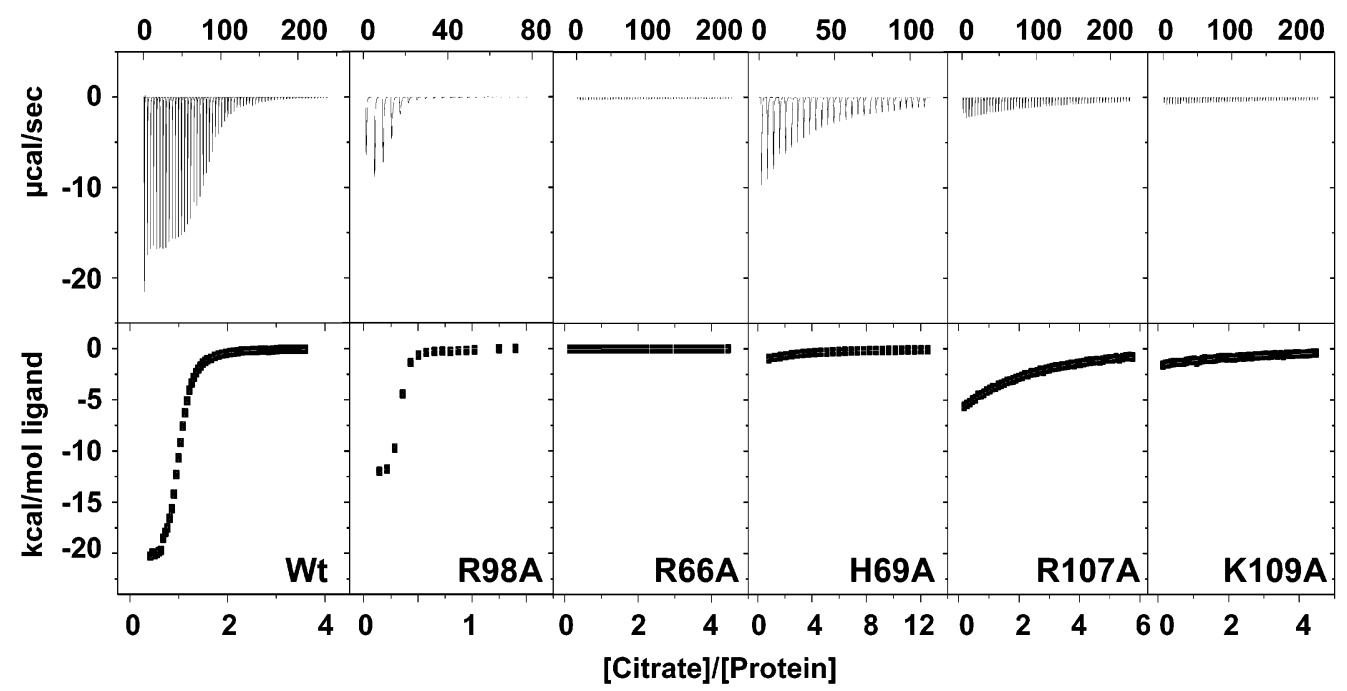

FIgURE 2: Citrate binding to wild-type CitAP (Wt) and muteins R98A, R66A, H69A, R107A, and K109A measured by ITC at $25{ }^{\circ} \mathrm{C}$. The upper panels show the heat changes observed upon injection of $3-10 \mu \mathrm{L}$ of a trisodium citrate solution in $50 \mathrm{mM}$ sodium phosphate buffer pH 7.0 into $1.40 \mathrm{~mL}$ of a protein solution in the same buffer. The lower panels show the integrated heat changes of each injection (normalized per mol citrate) plotted against the molar ratio of citrate to protein. The solid line represents a nonlinear least-squares fit according to a single-site binding model. The conditions for the individual experiments were as follows: $\mathrm{Wt}, 324 \mu \mathrm{M}$ protein, $6.48 \mathrm{mM}$ trisodium citrate, injection volume $3 \mu \mathrm{L}$ except for the first injection $(5 \mu \mathrm{L})$; R98A, $222 \mu \mathrm{M}$ protein, $4.40 \mathrm{mM}$ trisodium citrate, injection volume $5 \mu \mathrm{L}$; R66A, $1200 \mu \mathrm{M}$ protein, $60.0 \mathrm{mM}$ trisodium citrate, injection volume $5 \mu \mathrm{L}$; H69A, $580 \mu \mathrm{M}$ protein, 33.0 mM trisodium citrate, injection volume $10 \mu \mathrm{L}$; R107A, $78 \mu \mathrm{M}$ protein, $2.0 \mathrm{mM}$ trisodium citrate, injection volume $5 \mu \mathrm{L}$; K109A, $125 \mu \mathrm{M}$ protein, $2.5 \mathrm{mM}$ trisodium citrate, injection volume $5 \mu \mathrm{L}$.

position in the entire CitA protein, 42 has to be added to the numbers given here.

Isothermal Titration Calorimetry of the CitAP Muteins with Citrate as Ligand. The 17 CitAP muteins were analyzed for citrate binding by isothermal titration calorimetry, and the calorimetric data are summarized in Table 2. In Figure 2 , the binding curves for wild-type CitAP and particularly interesting muteins are shown. According to their $K_{\mathrm{d}}$ values, the muteins can be divided into three groups. The first one includes 12 proteins, whose $K_{\mathrm{d}}$ ranged between 0.7 - to 3.3-fold of the value of wild-type CitAP (i.e., R7A, H9A, R15A, K35A, R36A, R40A, K42A, R49A, K77A, K92A, $\mathrm{K} 99 \mathrm{~A}$, and K118A). The weak effect of these mutations on citrate binding argues against a direct participation of the corresponding residues in the binding process. As in wildtype CitAP, citrate binding of all muteins listed above was driven by the enthalpy change; however, in the case of muteins R7A, H9A, and R15A, the binding enthalpy was significantly decreased as compared to wild-type CitAP. This decrease was compensated by a gain of entropy. Enthalpyentropy compensation is known to be a general feature of many chemical reactions and processes in biological systems (22). More recently, it has been shown that redistribution of side chain entropy is an important factor influencing the thermodynamics of ligand binding events (23). On the basis of these observations and the ITC data, a different dynamics of the muteins R7A, H9A, and R15A can be hypothesized.

The second group identified by ITC includes only a single mutein, CitAP-R98A, which showed a 6-fold decreased $K_{\mathrm{d}}$ value of $0.8 \mu \mathrm{M}$ (Table 2, Figure 2). This increased affinity appears to be caused by the fact that the entropy change is less unfavorable than in the case of the wild-type protein. It seems likely that the $\mathrm{R} 98$ residue is located close to the citrate binding site and that the positively charged guanidinium group interferes with binding by influencing the protein movement, as indicated by the near-UV CD spectra described below. A remarkable feature of the R98A mutein was the low binding stoichiometry of $\sim 0.3$, which cannot be explained yet. As in the case of wild-type CitAP (15), titration of isocitrate or tricarballylate to the R98 mutein did not cause enthalpy changes attributable to binding, showing that the ligand specificity was unchanged.

The third group includes the four muteins R66A, H69A, R107A, und K109A, whose apparent $K_{\mathrm{d}}$ values are drastically increased (i.e., at least more than 38-fold (Table 2, Figure $2)$ ). For the R107A mutein a $K_{\mathrm{d}}$ of $205 \mu \mathrm{M}$ was determined, whereas the $K_{\mathrm{d}}$ of the other three muteins presumably was above $1 \mathrm{mM}$. For the latter proteins, a reliable quantitative evaluation of the ITC data was not possible. An entropically driven binding of citrate by the group III muteins cannot be completely excluded but seems very unlikely. Moreover, the CD spectra presented below argue against the possibility that the increased $K_{\mathrm{d}}$ values are due to misfolding. Therefore, the ITC data indicate that residues R66, H69, R107, and K109 are directly involved in citrate binding.

Secondary Structure Estimation. The secondary structure of wild-type CitAP and muteins R98A, R66A, H69A, R107A, and K109A was evaluated by far-UV CD spectroscopy. Typical spectra obtained for wild-type CitAP in free and complexed form are shown in Figure 3. The characteristic minima at 209 and $222 \mathrm{~nm}$ reflect the high content of $\alpha$-helical structure of approximately $40 \%$. Addition of excess citrate resulted in only minor differences of the spectra, which indicates the absence of significant folding processes induced by ligand binding. The spectra obtained for the mutant proteins in the absence and presence of citrate are similar to the spectra of wild-type CitAP, which excludes a significant 


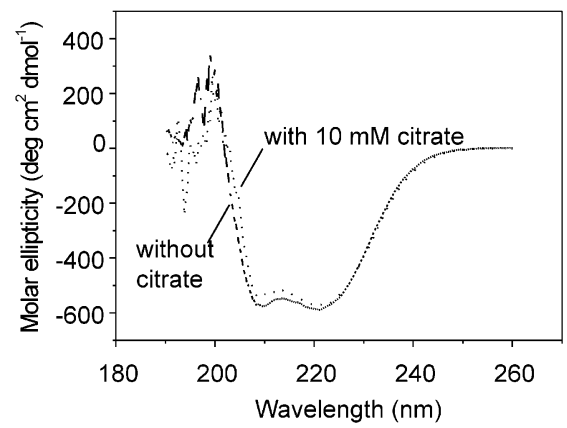

FIGURE 3: Far-UV CD spectrum of wild-type CitAP in the absence and presence of citrate. The measurement was performed with a $0.1 \mathrm{~cm}$ cuvette containing a $1 \mathrm{mg} / \mathrm{mL}$ protein solution in $50 \mathrm{mM}$ sodium phosphate buffer $\mathrm{pH}$ 7.0.

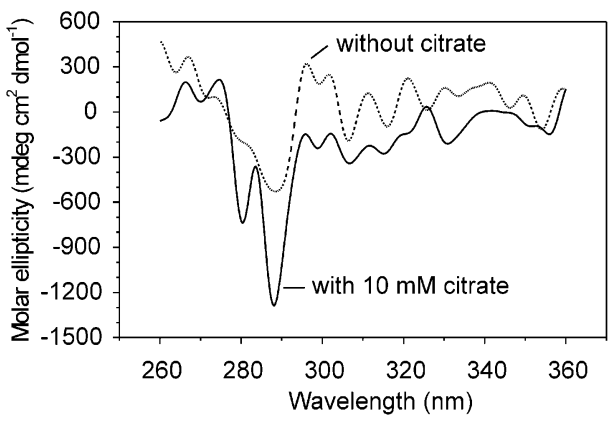

FIGURE 4: Near-UV CD spectrum of wild-type CitAP in the absence and presence of citrate. The measurement was performed with a $0.5 \mathrm{~cm}$ cuvette containing a $1 \mathrm{mg} / \mathrm{mL}$ protein solution in 50 $\mathrm{mM}$ sodium phosphate buffer $\mathrm{pH}$ 7.0.

influence of the amino acid exchanges on the secondary structure of the protein.

Near-UV CD Spectroscopy. To investigate changes of tertiary protein structure upon ligand binding, $\mathrm{CD}$ spectra were recorded in the near-UV range in the absence and presence of citrate. In the case of wild-type CitAP, a significant change of the spectrum was observed upon addition of citrate (Figure 4). The formation of the two minima at 281 and $287 \mathrm{~nm}$ indicates a structural rearrangement induced by ligand binding. The role of residues R98, R66, H69, R107, and K109 on this process was evaluated by analyzing the corresponding muteins. The alteration of the R107A spectrum upon addition of citrate was comparable to that of wild-type CitAP; therefore, a significant role of R107 for the rearrangement can be excluded. The spectra obtained from muteins R98A, H69A, R66A, and K109A in free and complexed form showed high similarity to the spectrum of the complexed wild-type protein. In the case of the high-affinity mutein R98A, the apparent lack of rearrangement is in agreement with the fact that the entropy loss upon citrate binding is smaller than in the case of wild-type CitAP and supports the idea that the guanidinium group of R98 may necessitate the structural rearrangement in wildtype CitAP upon ligand binding. The similarity of the nearUV CD spectra of H69A, R66A, and K109A to that of complexed wild-type CitAP indicates that the corresponding residues are involved in the changes of the tertiary structure upon ligand binding and that the replacement by alanine possibly has fixed the unliganded muteins in a more rigid conformation that resembles the liganded state of wild-type CitAP. This fixation could explain the drastically decreased citrate affinity of these three muteins.

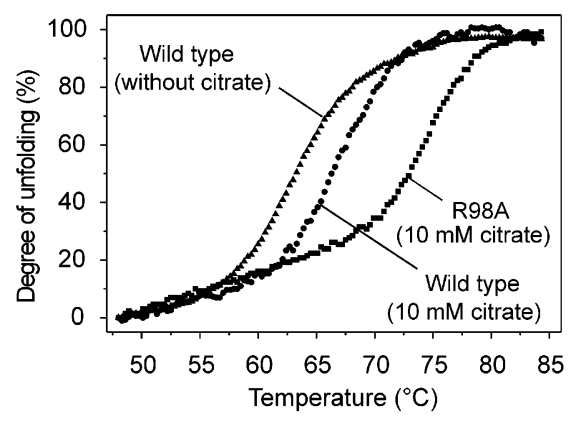

FIGURE 5: Thermal denaturation of wild-type CitAP and mutein R98A measured by CD spectroscopy at $218 \mathrm{~nm}$. The measurement was performed with a $0.1 \mathrm{~cm}$ cuvette containing a $1 \mathrm{mg} / \mathrm{mL}$ protein solution in $50 \mathrm{mM}$ sodium phosphate buffer $\mathrm{pH}$ 7.0. The temperature was increased from 25 to $90{ }^{\circ} \mathrm{C}$ at a rate of $30^{\circ} \mathrm{C} / \mathrm{h}$.

Table 3: Thermal Stability of Wild-Type CitAP and Selected Muteins $^{a}$

\begin{tabular}{lcccc}
\hline & $\begin{array}{c}T_{\mathrm{m}}\left({ }^{\circ} \mathrm{C}\right) \\
\text { without citrate }\end{array}$ & $\begin{array}{c}T_{\mathrm{m}}\left({ }^{\circ} \mathrm{C}\right) \\
\text { with citrate }\end{array}$ & $\begin{array}{c}T_{\mathrm{m}}(\text { mutein })- \\
T_{\mathrm{m}}(\mathrm{WT})\end{array}$ & $\begin{array}{c}T_{\mathrm{m}}(+ \text { citrate })- \\
T_{\mathrm{m}}(- \text { citrate })\end{array}$ \\
\hline Wrotein & $62.7 \pm 0.7$ & $68.9 \pm 2.0$ & n.a. & 6.2 \\
$\mathrm{R} 98 \mathrm{~A}$ & $65.8 \pm 0.3$ & $75.3 \pm 0.0$ & 3.1 & 9.5 \\
$\mathrm{R} 66 \mathrm{~A}$ & $69.5 \pm 0.1$ & $69.1 \pm 0.2$ & 6.8 & -0.4 \\
$\mathrm{H} 69 \mathrm{~A}$ & $67.1 \pm 0.1$ & $66.4 \pm 0.9$ & 4.4 & -0.7 \\
$\mathrm{R} 107 \mathrm{~A}$ & $68.5 \pm 0.6$ & $68.7 \pm 1.0$ & 5.8 & 0.2 \\
$\mathrm{~K} 109 A$ & $66.1 \pm 0.3$ & $67.7 \pm 0.3$ & 3.4 & 1.6 \\
\hline
\end{tabular}

${ }^{a}$ Thermal denaturation was monitored by CD spectroscopy at 218 $\mathrm{nm}$ using a $0.1 \mathrm{~cm}$ cuvette filled with dialyzed CitAP $(1 \mathrm{mg} / \mathrm{mL})$ in 50 $\mathrm{mM}$ sodium phosphate buffer $\mathrm{pH}$ 7.0. The temperature was increased from 25 to $90{ }^{\circ} \mathrm{C}$ at a rate of $30{ }^{\circ} \mathrm{C} / \mathrm{h}$. The midpoint of the transition curve $\left(T_{\mathrm{m}}\right)$ was determined by a fit to a two-state unfolding model following a standard protocol (21). N.A., not applicable.

Thermal Stability of Wild-Type CitAP and Relevant Muteins. The stability of wild-type CitAP and muteins R98A, R66A, H69A, R107A, and K109A in the absence and presence of citrate was evaluated by thermal denaturation experiments using CD spectroscopy at $218 \mathrm{~nm}$. As shown in Figure 5, the presence of citrate $(10 \mathrm{mM})$ shifted the $T_{\mathrm{m}}$ value of wild-type CitAP from 62.7 to $68.9^{\circ} \mathrm{C}$, showing significant stabilization of the protein structure by the bound ligand. The increased stability was found to be independent from the increased ionic strength of the buffer containing citrate (data not shown). As summarized in Table 3, the melting point of all five muteins analyzed in the absence of citrate was increased between 3.1 and $6.8^{\circ} \mathrm{C}$ as compared to wild-type CitAP, showing that the mutations have a stabilizing effect on the unliganded state of the protein. Citrate $(10 \mathrm{mM})$ did not significantly change the $T_{\mathrm{m}}$ values of the muteins with disturbed binding (R66A, H69A, R107A, K109A). Under the experimental conditions used, the fraction of the muteins having citrate bound was calculated to be between 59 (R66A) and 98\% (R107A) according to the $K_{\mathrm{d}}$ values given in Table 2. This indicates that a further stabilization by citrate is not possible in these mutants. By contrast, citrate increased the stability of the high-affinity receptor CitAP-R98A by $9.5^{\circ} \mathrm{C}$. Thus, high citrate binding affinity correlates with strong stabilization by citrate, and low binding affinity correlates with a lack of stabilization.

\section{DISCUSSION}

In this paper, we tested the influence of all arginine, lysine, and histidine residues in the periplasmic domain of the $K$. 


\begin{tabular}{|c|c|c|c|c|}
\hline species & SK & RR & regulated genes & $\begin{array}{c}\text { presumed or } \\
\text { verified ligand }\end{array}$ \\
\hline $\begin{array}{l}\text { Klebsiella } \\
\text { pneumoniae }\end{array}$ & CitA & CitB & $\begin{array}{l}\text { citS, oadGAB, citAB, } \\
\text { citCDEFG (5) }\end{array}$ & citrate $(15)$ \\
\hline E. coli & CitA & CitB & $\begin{array}{l}\text { citT, } \text { citCDEFXG (33), } \\
\text { and others (34) }\end{array}$ & $\begin{array}{l}\text { citrate, } \\
\quad \text { isocitrate (29) }\end{array}$ \\
\hline E. coli & DcuS & DcuR & $\boldsymbol{d c u B}, \operatorname{frd} A B C D(35,36)$ & $\begin{array}{l}\mathrm{C}_{4} \text { dicarboxylic } \\
\text { acids }(35-37)\end{array}$ \\
\hline B. subtilis & CitS & CitT & citM, yflN (38) & Mg-citrate (38) \\
\hline B. subtilis & DctS & DctR & $\operatorname{dct} P(28)$ & $\begin{array}{c}\mathrm{C}_{4} \text {-dicarboxylate binding } \\
\text { protein (DctB) and/or } \\
\mathrm{C}_{4} \text { dicarboxylates }(28)\end{array}$ \\
\hline
\end{tabular}

${ }^{a}$ The genes encoding carriers for citrate or $\mathrm{C}_{4}$-dicarboxylic acids are shown in boldface. $\mathrm{SK}$, sensor kinase; RR, response regulator.
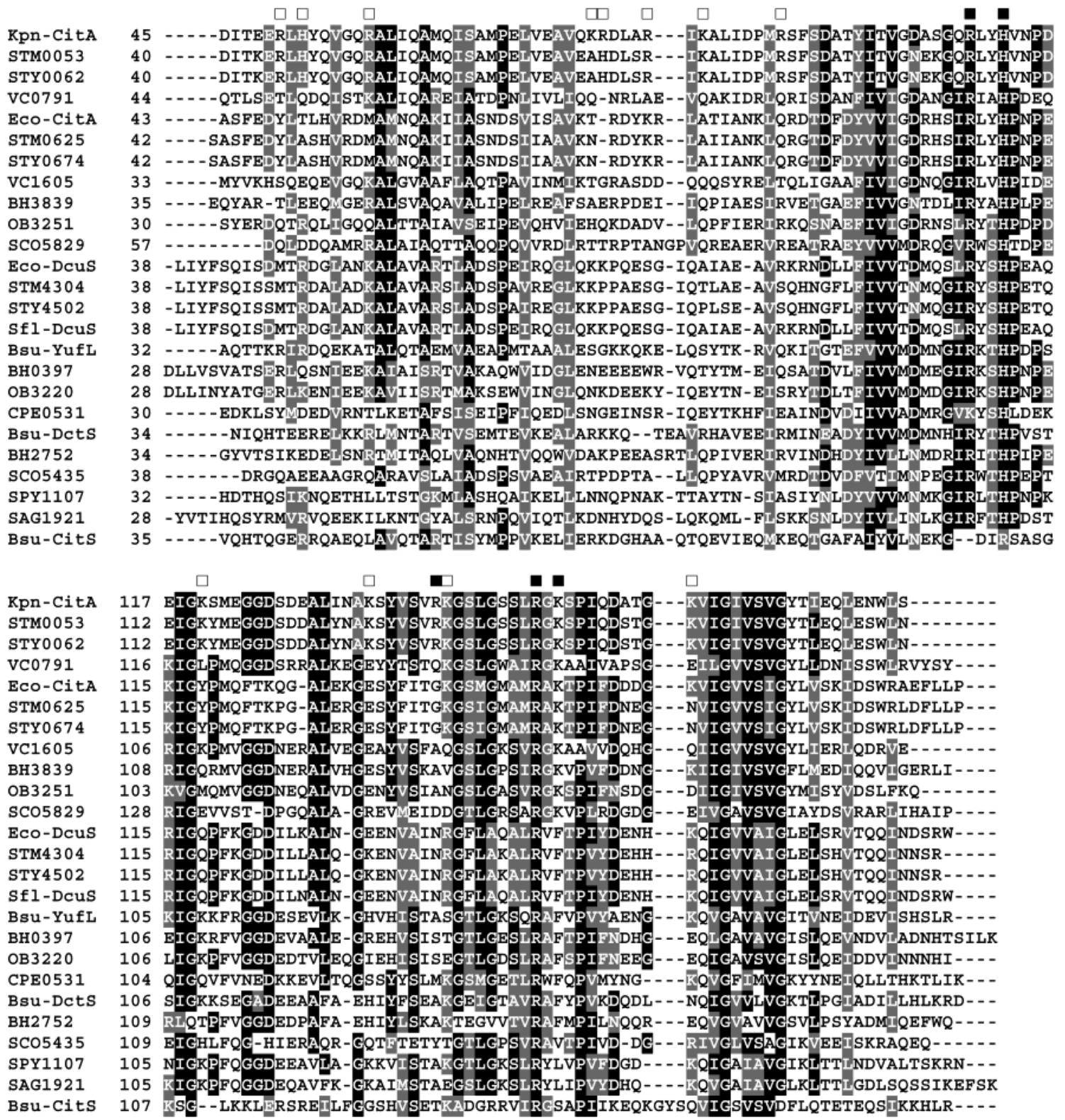

FIGURE 6: Alignment of the periplasmic domain of members of the CitA subfamily of sensor histidine kinases. The residues identified in this work with the $K$. pneumoniae sensor kinase CitA as important for citrate binding are marked by filled squares, those without a drastic effect on binding are indicated by open squares. Abbreviations: $\mathrm{BH}$, Bacillus halodurans; Bsu, B. subtilis; CPE, Clostridium perfringens; Eco, E. coli; Kpn, K. pneumoniae; OB, Oceanobacillus iheyensis; SAG, Streptococcus agalactiae; SCO, Streptomyces coelicolor; Sfl, Shigella flexneri; SPY, Streptococcus pyogenes; STM, S. tyhimurium; STY, S. typhi; and VC, Vibrio cholerae. Either the designation of the corresponding genes is given or the number according to the protein table of the entire genome (http://www.ncbi.nlm.nih.gov/ PMGifs/ Genomes/micr.html). 
pneumoniae sensor kinase CitA on citrate binding by replacing the corresponding residues with alanine. ITC analysis of the resulting 17 muteins led to the identification of five residues that are highly important for binding (Table 2 ). In four cases, the apparent $K_{\mathrm{d}}$ values were increased 38fold (R107A) or >300-fold (R66A, H69A, K109A). By contrast, the $K_{\mathrm{d}}$ value of the R98A mutein was 6-fold decreased. Thermal denaturation experiments (Table 3) revealed that citrate significantly stabilized wild-type CitAP and mutein R98A but had only weak effects on the four proteins with disturbed binding. Since the far-UV CD spectra did not reveal major changes of secondary structure in these mutants, a direct involvement of R98, R66, H69, R107, and K109 in citrate binding and related conformational changes of the protein appears likely.

The participation of positively charged residues in citrate binding has also been shown for other proteins. In citrate synthase from different species, three arginine and three histidine residues were identified as ligands by structural analysis $(24,25)$. Mutational analysis of the citrate chemoreceptor Tcp from Salmonella typhimurium suggested that three arginine residues and one lysine residue are involved in citrate recognition (26). However, as in the case of CitAP, other possibilities for the observed effects of the mutations cannot be strictly excluded without a structural analysis.

CitA of $K$. pneumoniae represents the first characterized member of a subfamily of sensor kinases that share significant sequence identity not only in the conserved kinase domain but also in the periplasmic domain (15). In the classification scheme by Grebe and Stock, this subfamily was designated $\mathrm{HPK}_{5}$ (27). Meanwhile, the function of several of these sensor kinases and their cognate response regulators have been characterized to some extent, and in all cases, a transporter for either citrate or $\mathrm{C}_{4}$-dicarboxylic acids was found to be induced by the corresponding twocomponent systems (Table 4). In addition, many homologues of CitA (and its cognate response regulator CitB) were identified in the course of bacterial genome sequencing projects but not yet characterized. From an alignment of the periplasmic domains of the CitA homologues (Figure 6), it is evident that three of the residues essential for citrate binding in K. pneumoniae CitA (i.e., R66, H69, and R107) are highly conserved within the homologues. Thus, it appears possible that these residues are critical for ligand binding also in other members of the CitA family. In the case of the Bacillus subtilis $\mathrm{C}_{4}$-dicarboxylate sensor/regulator pair DctS/ DctR, the periplasmic binding protein DctB was shown to be essential for induction of the dicarboxylate carrier DctP (28), indicating an involvement of DctB in the sensing of dicarboxylates. It appears possible that an interaction between ligand-bound DctB and DctS regulates the autophosphorylation activity of DctS instead of or in addition to binding of $\mathrm{C}_{4}$-dicarboxylates by DctS itself.

In contrast to R66, H69, and R107, residue K109 was conserved in only about half of the homologues, whereas the other half contained phenylalanine, leucine, valine, or serine at this position (Figure 6). According to the currently characterized members of the CitA family, it appears possible that lysine is preferred at this position in those members of the CitA family that bind tricarboxylic acids, whereas it is mostly absent in members that eventually bind $\mathrm{C}_{4}$-dicarboxylic acids.
In the case of residue R98, only two homologues from $S$. typhimurium and Salmonella typhi also have an arginine residue at this position, whereas no other homologues contain a positively charged residue at this position. In the case of E. coli CitA, a glycine residue (G138) is present instead of an arginine residue. The periplasmic domain of E. coli CitA (comprising residues 38-177 with a C-terminal hexahistidine tag, named $\mathrm{CitAP}_{\mathrm{Ec}}$ ) was also shown to function as a citrate receptor with a $K_{\mathrm{d}}$ of about $0.5 \mu \mathrm{M}$ in $50 \mathrm{mM}$ sodium phosphate buffer pH 7.0 as measured by ITC (29). Since this $K_{\mathrm{d}}$ value is very similar to that of CitAP-R98A from $K$. pneumoniae, we wondered whether an exchange of Gly102 (corresponds to G138 in the entire protein) in CitAP $\mathrm{Ec}_{\mathrm{Ec}}$ by arginine would result in a $\sim 6$-fold increased $K_{\mathrm{d}}$ value. The corresponding mutein $\mathrm{CitAP}_{\mathrm{Ec}}-\mathrm{G} 102 \mathrm{R}$ precipitated when dialyzed against $50 \mathrm{mM}$ sodium phosphate buffer, $\mathrm{pH} 7$, indicating that the exchange has significantly altered the physicochemical properties of the protein. ITC binding studies were performed in a buffer in which the mutein did not precipitate (i.e., TNI400 buffer consisting of $20 \mathrm{mM}$ Tris, $500 \mathrm{mM} \mathrm{NaCl}$, and $400 \mathrm{mM}$ imidazole adjusted to $\mathrm{pH}$ 7.9). No binding of citrate to $\mathrm{CitAP}_{\mathrm{Ec}}-\mathrm{G} 102 \mathrm{R}$ was observed, whereas wild-type $\mathrm{CitAP}_{\mathrm{Ec}}$ had a $K_{\mathrm{d}}$ value of $2.3 \mu \mathrm{M}$ for citrate in this buffer (29). Although it cannot be excluded that the G102R exchange caused structural changes, its dramatic effect on citrate binding supports the conclusion drawn from the R98A mutation in $K$. pneumoniae CitAP that the corresponding position is critical for citrate binding.

In this paper, the effects of replacing arginine, lysine, and histidine residues by alanine on citrate binding by the isolated periplasmic domain of the sensor kinase CitA was tested. Our future studies will focus on the structural analysis of CitAP and on the consequences of the amino acid exchanges on the signaling properties of the entire sensor kinase CitA. For this purpose, an in vivo system has to established that allows us to measure the expression of target genes of the CitA-CitB two-component system (e.g., citS or citC).

\section{ACKNOWLEDGMENT}

The authors thank Dean Madden for valuable comments on the manuscript and Hermann Sahm for continuous support.

\section{REFERENCES}

1. Stock, J. B., Ninfa, A. J., and Stock, A. M. (1989) Microbiol. Rev. 53, 450-490.

2. Bourret, R. B., Borkovich, K. A., and Simon, M. I. (1991) Annu. Rev. Biochem. 60, 401-441.

3. Parkinson, J. S., and Kofoid, E. C. (1992) Annu. Rev. Genet. 26, $71-112$.

4. Robinson, V. L., Buckler, D. R., and Stock, A. M. (2000) Nature Struct. Biol. 7, 626-633.

5. Bott, M., Meyer, M., and Dimroth, P. (1995) Mol. Microbiol. 18, 533-546.

6. Meyer, M., Dimroth, P., and Bott, M. (1997) J. Mol. Biol. 269, 719-731.

7. Van der Rest, M. E., Siewe, R. M., Abee, T., Schwarz, E., Oesterhelt, D., and Konings, W. N. (1992) J. Biol. Chem. 267, 8971-8976.

8. Bott, M., and Dimroth, P. (1994) Mol. Microbiol. 14, 347-356.

9. Schneider, K., Dimroth, P., and Bott, M. (2000) FEBS Lett. 483, $165-168$.

10. Schneider, K., Dimroth, P., and Bott, M. (2000) Biochemistry 39, 9438-9450.

11. Schwarz, E., Oesterhelt, D., Reinke, H., Beyreuther, K., and Dimroth, P. (1988) J. Biol. Chem. 263, 9640-9645. 
12. Laussermair, E., Schwarz, E., Oesterhelt, D., Reinke, H., Beyreuther, K., and Dimroth, P. (1989) J. Biol. Chem. 264, 1471014715 .

13. Woehlke, G., Laussermair, E., Schwarz, E., Oesterhelt, D., Reinke, H., Beyreuther, K., and Dimroth, P. (1992) J. Biol. Chem. 267, 22804-22805.

14. Meyer, M., Dimroth, P., and Bott, M. (2001) J. Bacteriol. 183, 5248-5256.

15. Kaspar, S., Perozzo, R., Reinelt, S., Meyer, M., Pfister, K., Scapozza, L., and Bott, M. (1999) Mol. Microbiol. 33, 858-872.

16. Studier, F. W., and Moffatt, B. A. (1986) J. Mol. Biol. 189, $113-$ 130.

17. Sanger, F., Nicklen, S., and Coulson, A. R. (1977) Proc. Natl. Acad. Sci. U.S.A. 74, 5463-5467.

18. Gill, S. C., and von Hippel, P. H. (1989) Anal. Biochem. 182, 319-326.

19. Schaffer, S., Weil, B., Nguyen, V. D., Dongmann, G., Günther, K., Nickolaus, M., Hermann, T., and Bott, M. (2001) Electrophoresis 22, 4404-4422.

20. Wiseman, T., Williston, S., Brandts, J. F., and Lin, L. N. (1989) Anal. Biochem. 179, 131-137.

21. Pace, N. C., and Scholtz, J. M. (1997) in Protein structure: a practical approach (Creighton, T. E., Ed.), 2nd ed., pp 299-321, University Press, Oxford.

22. Dunitz, J. D. (1995) Chem. Biol. 2, 709-712.

23. Lee, A. L., Kinnear, S. A., and Wand, A. J. (2000) Nature Struct. Biol. 7, 72-77.

24. Remington, S., Wiegand, G., and Huber, R. (1982) J. Mol. Biol. $158,111-152$.
25. Russell, R. J., Ferguson, J. M., Hough, D. W., Danson, M. J., and Taylor, G. L. (1997) Biochemistry 36, 9983-9994.

26. Iwama, T., Nakao, K. I., Nakazato, H., Yamagata, S., Homma, M., and Kawagishi, I. (2000) J. Bacteriol. 182, 1437-1441.

27. Grebe, T. W., and Stock, J. B. (1999) Adv. Microb. Physiol. 41, 139-227.

28. Asai, K., Baik, S. H., Kasahara, Y., Moriya, S., and Ogasawara, N. (2000) Microbiology 146, 263-271.

29. Kaspar, S., and Bott, M. (2002) Arch. Microbiol. 177, 313-321.

30. Wootton, J. C., and Drummond, M. H. (1989) Prot. Eng. 2, 535543.

31. Taylor, B. L., and Zhulin, I. B. (1999) Microbiol. Mol. Biol. Rev $63,479-506$

32. Indyk, L., and Fisher, H. F. (1998) Methods Enzymol. 295, 350364.

33. Ingmer, H., Miller, C. A., and Cohen, S. N. (1998) Mol. Microbiol. $29,49-59$.

34. Oshima, T., Aiba, H., Masuda, Y., Kanaya, S., Sugiura, M. Wanner, B. L., Mori, H., and Mizuno, T. (2002) Mol. Microbiol. 46, 281-291.

35. Zientz, E., Bongaerts, J., and Unden, G. (1998) J. Bacteriol. 180, $5421-5425$.

36. Golby, P., Davies, S., Kelly, D. J., Guest, J. R., and Andrews, S. C. (1999) J. Bacteriol. 181, 1238-1248.

37. Janausch, I. G., Garcia-Moreno, I., and Unden, G. (2002) J. Biol. Chem. 277, 39809-39814.

38. Yamamoto, H., Murata, M., and Sekiguchi, J. (2000) Mol. Microbiol. 37, 898-912.

$\mathrm{BI} 0340595$ 